\title{
Simvastatin and Recombinant Antagonist of Receptors of Interleukin-1 Modulate Toll-like Receptors in Experimental Acute Ileitis in Rat
}

\author{
Aleksandr Zherebiatiev ${ }^{1 *}$, Aleksandr Kamyshnyi ${ }^{1}$ \\ ${ }^{1}$ Department of Microbiology, Virology, and Immunology, Zaporozhye State Medical University, Zaporozhye, Ukraine.
}

Received: 22 Jul 2014

Revised : 20 Aug 2014

Accepted: 25 Aug 2014

Corresponding Authors: Aleksandr Zherebiatiev

Senior technician of Department of Microbiology, Virology, and Immunology, Zaporozhye State Medical University, Mayakovsky avenue 26, Zaporozhye, 69035, Ukraine

Phone: +380967959937

E-mail: Gerya2009@yandex.ru

\begin{abstract}
Background: The pathogenesis of inflammatory bowel disease is complex and multifactorial. Studies have led to the current concept that Toll-like receptors represent key mediators of innate host defense in the intestine, and they are involved in maintaining mucosal as well as commensal homeostasis. We studied the possibility of simvastatin and antagonist of receptors of interleukin-1 for pharmacological correction of acute ileitis in rats with a focus on the expression intensity studies of TLR2 TLR4 with lymphocytes of small intestine.

Materials and Methods: Experiments were carried out on male Wistar rats aged 5-7 months (body mass 260-285 g). Rats were divided into four experimental groups: group 1- control; group 2- rats with indomethacin-induced ileitis; group 3rats given simvastatin ( $20 \mathrm{mg} / \mathrm{kg}$, for 5 days, subcutaneously); group 4- rats given antagonist of receptors of interleukin-1 ( $3 \mathrm{mg} / \mathrm{kg}$, for 5 days, subcutaneously). The TLR2 and TLR4 immunopositive lymphocytes were determined using a direct immunofluorescence technique with using a monoclonal rat antibody.

Results: We established that development of ileitis was accompanied with the change of amount of TLR2 ${ }^{+}$and TLR4 ${ }^{+}$lymphocytes and the density of TLR2, TLR4 in immunopositive cells. Drug administration during the development of experimental pathology was accompanied by changes in the expression of TLR2, TLR4 and their density on lymphocytes.

Conclusions: Simvastatin and antagonist of receptors of interleukin-1 seemed to be beneficial in indomethacin-induced rat ileitis model through modulate TLR2 and TLR4 expression with lymphocytes of small intestine.
\end{abstract}

Keywords: Ileitis; Recombinant antagonist of receptors of interleukin-1 (ARIL1); Simvastatin; Toll-like receptor

Please cite this article as: Zherebiatiev A, Kamyshnyi A. RNAi Technology: Simvastatin and Recombinant Antagonist of Receptors of Interleukin-1 Modulate Toll-like Receptors in Experimental Acute Ileitis in Rat. Res Mol Med. 2014; 2 (3): $11-16$

\section{Introduction}

Crohn's disease and ulcerative colitis are the main clinical phenotypes of inflammatory bowel disease (IBD). Both forms of IBD can increase the incidence of gastrointestinal and colon cancers, and both ones are associated with significant morbidity and mortality worldwide. In addition, they can begin early in life and persist for long periods (1). The pathogenesis of IBD is complex and multifactorial. Differential alteration of Toll-like receptor (TLR) expression in inflammatory bowel disease was first described 15 years ago. Studies have led to the current concept that TLRs represent key mediators of innate host defense in the intestine, and they involved in maintaining mucosal as well as commensal homeostasis. Recent findings in diverse murine models of ileitis have helped to reveal the importance mechanisms of TLR dysfunction in IBD pathogenesis (2).

Statin drugs are widely used worldwide for treatment of hyperlipidemia in addition to cholesterol-lowering effect, statins reduce many of the mediators involved in IBD-specific inflammation including C-reactive protein, interferon gamma, interleukins 6 and 8 , and NF-kappa B (3). 
Cytokines, such as tumor necrosis factor (TNF- $\alpha$ ) and interleukin (IL-1), play a major role in the development of IBD. The naturally occurring inhibitor IL-1 receptor antagonist (IL-1Ra) in part, regulates activities of IL-1. IL-1Ra specifically inhibits IL-1 activities by binding to IL-1 receptors neutralization of endogenous IL-1Ra increases the severity of intestinal inflammation, indicating that endogenous IL-1Ra plays an anti-inflammatory role. These observations suggest that IL-1 is one of the critical mediators of intestinal inflammation in IBD (4).

Therefore the aim of this study was to investigate the effect of acute ileitis on expression intensity of TLR2 and TLR4 with lymphocytes of small intestine, and investigate the possibility of Simvastatin and antagonist of receptors of interleukin-1 (ARIL-1) for pharmacological correction of ileitis in rats.

\section{Materials and methods}

Animals and tissue isolation

Experiments were carried out on male Wistar rats aged 5-7 months (body mass 260-285 g). The animals were bred at the Animal Facility of the Institution of Molecular Biology and Genetics (National Academy of Science of Ukraine, Kyiv). All animals were treated in compliance with the guidelines established by the Institutional Animal Care. Rats were kept under standard conditions, which include 12-h light/dark cycle, temperature: 18$20{ }^{\circ} \mathrm{C}$. The rats were given water and fed the standard laboratory diet ad libitum with no restriction prior to indomethacin injection. Single animals were fasted overnight and sacrificed by cervical dislocation after receiving an overdose of ether for the isolation of gut tissue. Rats were euthanized 4 days after induction of ileitis. The entire gut was examined and the bowel was opened antimesenterically. Macroscopic appearance of inflammation was scored as described specifically for indomethacin-induced ileitis (5). After removal of the small intestine the tissue was flushed with cold phosphate buffered saline. Peyer's patches were identified by visual inspection. For histochemical studies, they were removed and segments were fixed in formalin. After paraffin embedding $5 \mu \mathrm{m}$ sections were cut and stained with a monoclonal antibody.

\section{Drugs}

Simvastatin was obtained from Sigma-Aldrich (St. Louis, MO) and prepared as a $4 \mathrm{mg} / \mathrm{ml}$ stock. Briefly, $4 \mathrm{mg}$ was dissolved in $100 \mu \mathrm{l}$ of ethanol and $150 \mu \mathrm{l}$ of $0.1 \mathrm{~N} \mathrm{NaOH}$, incubated at $50{ }^{\circ} \mathrm{C}$ for $2 \mathrm{~h}$, and then $\mathrm{pH}$ adjusted to 7 and volume corrected to $1 \mathrm{ml}$. It was chemically activated by alkaline hydrolysis before subcutaneous injection. ARIL-1 was kindly provided by Resbio. LLC (St. Petersburg, Russia). Substance
ARIL-1 consists of 153 amino acids obtained by genetic engineering technology. The substance is lyophilized protein IL-1ra, which produced by a recombinant strain $E$. coli BL21.

\section{Indomethacin-induced ileitis}

For induction of an acute ileitis, rats received one subcutaneous dose of indomethacin $15 \mathrm{mg} / \mathrm{kg}$. Indomethacin was obtained from Sigma-Aldrich (St. Louis, MO).

\section{Animal groups}

Rats were divided into four experimental groups: group 1; control, group 2; rats with indomethacininduced ileitis, group 3; rats given simvastatin (20 $\mathrm{mg} / \mathrm{kg}, 2 \mathrm{ml} / \mathrm{kg}$ in the mixture of ethanol, $\mathrm{H}_{2} \mathrm{O}$, $\mathrm{NaOH}$ and $\mathrm{HCl}$ for 5 days, subcutaneously), group 4; rats given ARIL-1 (3 mg/kg, $2 \mathrm{ml} / \mathrm{kg}$ in the phosphate buffer solution (PBS) for 5 days, subcutaneously).

\section{Immunohistochemical staining}

After deparaffinization sections were rehydrated in graded ethanol (100\% twice, $90 \%$ once, $80 \%$ once, and $70 \%$ once, each for $5 \mathrm{~min}$ ), washed in PBS (twice, $5 \mathrm{~min}$ each). After rinsing in $0.1 \mathrm{M} \mathrm{PBS}$, the sections were incubated for $1 \mathrm{~h}$ at room temperature with anti-TLR2 or anti-TLR4 (1:50; Santa Cruz Biotechnology) FITC-conjugated antibodies. While protected from direct light exposure, samples were washed three times in PBS and mounted. Fluorescent images were obtained with a fluorescence microscope PrimoStar (ZEISS, Germany) with a computer-assisted video system AxioCam 5c (ZEISS, Germany). Fluorescent signal intensity was quantified using ImageJ software(NIH Image version 1.46). The levels of TLR2 and TLR4 expression were expressed as the relative mean fluorescence intensity in arbitrary units (AU). The lamina propria of mucous layer (LP) and isolated lymphoid follicles (ILF) were studied.

\section{Statistical analysis}

Results were statistically treated with Student's t-test using STATISTICA 6.0 (StatSoft Inc. 2001, USA) and presented as mean \pm SEM. Statistical differences were considered significant if the $\mathrm{P}$ value was $<0.05$.

\section{Results}

The macroscopic aspect of small bowel inflammation typical of indomethacin-induced ileitis in rats was a discontinuous transmural inflammation with multiple ulcerations and erosions of the small bowel with hyperaemic and haemorrhagic lesions. The study of serial sections of ileum showed that the development of acute ileitis was accompanied with onedirectedtendency on increasing of total number of 
TLR2 immunopositive lymphocytes (TLR2+) and decreasing of total number of TLR4 immunopositive lymphocytes (TLR4+) in lymphoid structures of ileum. Thus, quantity of TLR2+ cells is increased in LP by $19 \%(p<0.05)$, in ILF by $92 \%(p<0.05)$ in comparison with control (Figure 1A). Quantity of $\mathrm{TLR} 4^{+}$cells is decreased twice (in LP, $\mathrm{p}<0.05$ ), by $45 \%$ (in ILF, $\mathrm{p}<0.05$ ) in comparison with control (Figure 1D).
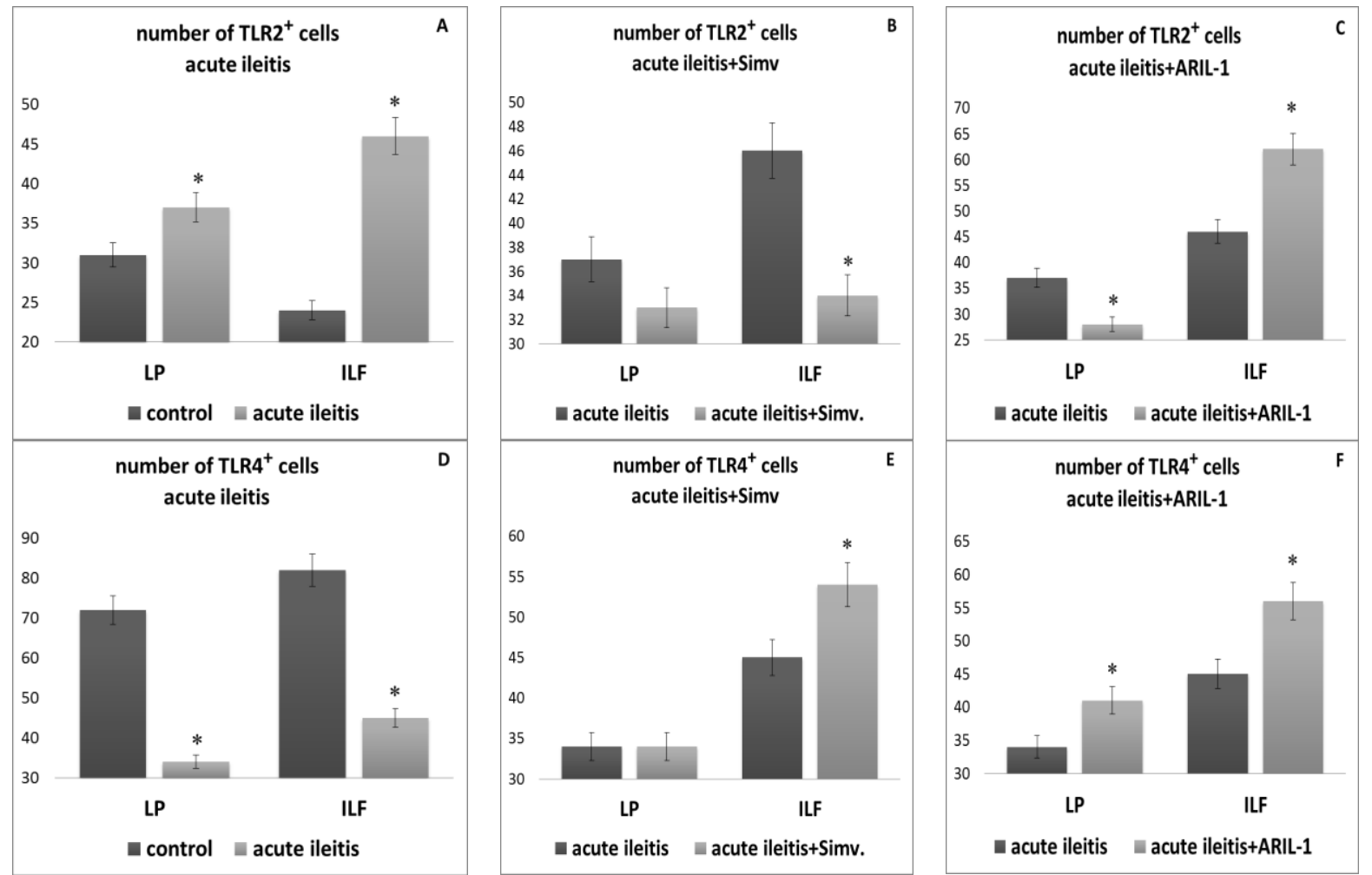

Figure 1. The number (on $1 \mathrm{~mm}^{2}$ ) of TLR2 ${ }^{+}$, TLR4 ${ }^{+}$cells in lamina propria of mucous layer (LP) and in isolated lymphoid follicles (ILF). The development of acute ileitis (A, D). The administration of Simvastatin (B, E) or ARIL-1 (C, F) to experimental animals during the development of acute ileitis. Note: * $\mathrm{P}<0.05$

The measuring of fluorescence intensity of TLR2 ${ }^{+}$ lymphocytes expressing the TLR2 showed reliable increase of this parameter in TLR2 ${ }^{+}$-small lymphocytes (in LP, $\mathrm{p}<0.05$ ) and $\mathrm{TLR}^{+}{ }^{+}$lymphoblasts (in ILF, $\mathrm{p}<0.05$ ), but the decrease in $\mathrm{TLR} 2{ }^{+}$-small lymphocytes (in ILF, $\mathrm{p}<0.05$ ) in comparison with control (Table 1).

Table 1. Density of TLR2 in immunopositive cells (fluorescence intensity, A.U.)

\begin{tabular}{|c|c|c|c|}
\hline Animal groups & TLR2 $^{+}$lymphoblasts & TLR2 $^{+}$medium lymphocytes & TLR2 $^{+}$small lymphocytes \\
\hline \multicolumn{4}{|c|}{ Lamina propria } \\
\hline Control $(n=10)$ & $0.562 \pm 0.012$ & $0.321 \pm 0.003$ & $0.143 \pm 0.002$ \\
\hline Acute ileitis $(n=10)$ & $0.590 \pm 0.012$ & $0.314 \pm 0.002$ & $0.149 \pm 0.002^{*}$ \\
\hline Acute ileitis $+\operatorname{simvastatin}(n=10)$ & $0.731 \pm 0.012^{\#}$ & $0.323 \pm 0.004$ & $0.138 \pm 0.003^{\#}$ \\
\hline Acute ileitis + ARIL-1 $(n=10)$ & $0.560 \pm 0.012$ & $0.329 \pm 0.004^{\#}$ & $0.142 \pm 0.003$ \\
\hline \multicolumn{4}{|c|}{ Isolated lymphoid follicles } \\
\hline Control $(n=10)$ & $0.511 \pm 0.012$ & $0.313 \pm 0.003$ & $0.165 \pm 0.002$ \\
\hline Acute ileitis $(n=10)$ & $0.588 \pm 0.014^{*}$ & $0.316 \pm 0.002$ & $0.156 \pm 0.002^{*}$ \\
\hline Acute ileitis $+\operatorname{simvastatin}(n=10)$ & $0.703 \pm 0.013^{\#}$ & $0.318 \pm 0.004$ & $0.139 \pm 0.003^{\#}$ \\
\hline Acute ileitis + ARIL-1 $(n=10)$ & $0.586 \pm 0.011$ & $0.320 \pm 0.004$ & $0.140 \pm 0.003^{\#}$ \\
\hline
\end{tabular}

Means \pm SEM are shown; $\mathrm{n}$ is the number of animals in each group. ${ }^{*}$ Significantly different $(\mathrm{P}<0.05)$ compared to control group. ${ }^{\#}$ Significantly different $(\mathrm{P}<0.05)$ compared to acute ileitis group. 
The measuring of fluorescence intensity of $\mathrm{TLR}^{+}$lymphocytes expressing the TLR4 showed reliable increase of this parameter in TLR $4^{+}$- medium lymphocytes (in LP, $\mathrm{p}<0.05$ ) and $\mathrm{TLR}^{+}{ }^{+}$small lymphocytes by $15 \%$ (in ILF, $\mathrm{p}<0.05$ ), but the decrease in TLR2 ${ }^{+}$-lymphoblasts by $10 \%$ (in LP, $\mathrm{p}<0.05$ ) in comparison with control (Table 2)

The administrations of Simvastatin in experimental animals during the development of experimental pathology was accompanied by decrease of TLR2 ${ }^{+}$ cells by $11 \%$ (in LP, $\mathrm{p}<0.05$ ), by $26 \%$ (in ILF, $\mathrm{p}<0.05$ ) in comparison with acute ileitis (Figure 1B). Quantity of TLR4 $4^{+}$cells is increased by $20 \%$ (in ILF, $\mathrm{p}<0.05$ ) in comparison with acute ileitis (Figure 1E). At the same time, the study of TLR2 and TLR4 expression in immunopositive cells showed that the administrations of Simvastatin were accompanied with different-directed changes of the given parameter in lymphoblasts and small lymphocytes and did not influence the level of its expression in medium lymphocytes (Table 1, 2).
The administrations of ARIL-1 to experimental animals during the development of experimental pathology was accompanied by the decrease of $\mathrm{TLR}^{+}$cells by $24 \%$ (in LP, $\mathrm{p}<0.05$ ), but increase by $35 \%$ (in ILF, $\mathrm{p}<0.05$ ) in comparison with acute ileitis (Figure 1C). Quantity of TLR4 ${ }^{+}$cells is increased by $21 \%$ (in LP, $\mathrm{p}<0.05$ ), by $24 \%$ (in ILF, $\mathrm{p}<0.05$ ) in comparison with acute ileitis (Figure 1F). The measuring of fluorescence intensity of $\mathrm{TLR}^{+}-$ lymphocytes expressing the TLR2 showed reliable increase of this parameter in TLR2 $2^{+}$-medium lymphocytes (in LP, $\mathrm{p}<0.05$ ) and the decrease in TLR2 ${ }^{+}$-small lymphocytes by $10 \%$ (in ILF, $\mathrm{p}<0.05$ ), in comparison with control (Table 1). The measuring of fluorescence intensity of $\mathrm{TLR} 4^{+}$-lymphocytes expressing the TLR4 showed reliable decrease of this parameter in TLR4 ${ }^{+}$-small lymphocytes by $10 \%$ (in LP, $\mathrm{p}<0.05$ ) and TLR4 ${ }^{+}$-lymphoblasts by $11 \%$ (in PP Lf, $\mathrm{p}<0.05$ ), in comparison with control (Table 2).

Table 2. Density of TLR4 in immunopositive cells (fluorescence intensity, A.U.)

\begin{tabular}{llcc}
\hline Animal groups & TLR4 ${ }^{+}$lymphoblasts & TLR4 ${ }^{+}$medium lymphocytes & TLR4 ${ }^{+}$small lymphocytes \\
\hline \multicolumn{2}{c}{ Lamina propria } \\
\hline Control $(n=10)$ & $0.685 \pm 0.012$ & $0.314 \pm 0.002$ & $0.137 \pm 0.002$ \\
Acute ileitis $(n=10)$ & $0.617 \pm 0.013^{*}$ & $0.324 \pm 0.004^{*}$ & $0.158 \pm 0.004^{*}$ \\
Acute ileitis + simvastatin $(n=10)$ & $0.676 \pm 0.025^{\#}$ & $0.316 \pm 0.005$ & $0.139 \pm 0.003^{\#}$ \\
Acute ileitis + ARIL-1 $(n=10)$ & $0.632 \pm 0.016$ & $0.321 \pm 0.004$ & $0.142 \pm 0.004^{\#}$ \\
\hline & \multicolumn{1}{c}{ Isolated lymphoid follicles } & $0.139 \pm 0.002$ \\
\hline Control $(n=10)$ & $0.653 \pm 0.012$ & $0.316 \pm 0.002$ & $0.144 \pm 0.003$ \\
Acute ileitis $(n=10)$ & $0.621 \pm 0.012$ & $0.319 \pm 0.003$ & $0.136 \pm 0.002^{\#}$ \\
Acute ileitis + simvastatin $(n=10)$ & $0.667 \pm 0.023$ & $0.313 \pm 0.004$ & $0.137 \pm 0.003$ \\
Acute ileitis + ARIL-1 $(n=10)$ & $0.572 \pm 0.014^{\#}$ & $0.322 \pm 0.004$ &
\end{tabular}

Means \pm SEM are shown; $\mathrm{n}$ is the number of animals in each group. . Significantly different $(\mathrm{P}<0.05)$ compared to control group. ${ }^{\#}$ Significantly different $(\mathrm{P}<0.05)$ compared to acute ileitis group.

\section{Discussion}

We found low TLR4 expression in samples of inflamed tissues but these results do not corroborate recent studies Hausmann et al because they have described low TLR4 expression by IECs in healthy human biopsies and significantly increased expression of TLR4 in patients with IBD (6).

Lee et al demonstrated that simvastatin inhibits proinflammatory gene expression by blocking NFkappaB signaling in IEC, and attenuates DSSinduced acute murine colitis, and could be a potential agent for the treatment of IBD (7). Most studies characterizing TLR function have focused on the intestinal epithelium and of the innate immune system cells, but there is also evidence that TLRs are important for adaptive immune cell function. TLRs influence T- and B- lymphocyte activity, and most studies in this area have focused on TLR signaling in regulatory $\mathrm{T}\left(\mathrm{T}_{\mathrm{Reg}}\right)$ and $\mathrm{Th}-17$ cells. The initial characterization of human TLR4 revealed expression in both $\gamma \delta$-and $\alpha \beta$-T cells in addition to APCs (8). Subsequent work cloning murine TLR2, a receptor for bacterial lipopeptides, revealed constitutive TLR2 and TLR4 expression in T cells; TLR2 expression was further enhanced through $\mathrm{T}$ cell receptor (TCR) activation (9). For $\mathrm{CD}^{+} \mathrm{T}$ cells, the expression of almost all known TLRs has been identified at the mRNA level (10). However, whether $\mathrm{CD}^{+} \mathrm{T}$ cells are capable of expressing all TLR proteins is debatable (11). Myd88 ${ }^{-/-} \mathrm{CD}^{+} \mathrm{T}$ cells exhibit reduced proliferation in response to TLR activation, and MyD88-deficient $\mathrm{CD}^{+} \mathrm{T}$ cells are unable to induce colitis (12). Similarly, MyD88-deficient $\mathrm{CD}^{+}{ }^{+} \mathrm{T}$ cells were defective in expansion, 
IFN $\gamma$ production, and ability to promote colitis under lymphopenic conditions (13). TLR4-deficient T cells exacerbated disease in a $\mathrm{CD} 4^{+} \mathrm{T}$ cell transfer colitis model (14), in which LPS treatment caused $\mathrm{CD}^{+} \mathrm{T}$ cells to lose IFN $\gamma$ but unregulated IL-17expression. In vivo, the loss of TLR4 selectively in $\mathrm{CD}^{+} \mathrm{T}$ cells led to decreased IFN $\gamma$ and IL-17 production only at the site of inflammation, not in the periphery, further indicating that TLR4 is not involved in the initial generation of Th1 or Th17 cells. TLR 2 signaling in $\mathrm{CD}^{+} \mathrm{T}$ cells promotes $\mathrm{Th} 1$ cell function, or at least IFN $\gamma$ production. In addition to influencing Th1 cell function, TLR2 signaling may directly influence the development and function of Th17 cells, a distinct $\mathrm{CD}^{+}$Th cell subset characterized by IL-17 production and pro-inflammatory activity (15). Thus, we observed an increase of the amount of $\mathrm{TLR}^{+}$ lymphocytes, with development of acute ileitis, could promote Th1 and Th17 differentiation and enhance pro-inflammatory signaling in the intestine.

Our results about the ability of simvastatin to affect the level of expression of TLR and proinflammatory signaling in the gut are indirectly confirmed by other authors. Simvastatin has been shown to inhibit acute as well as chronic inflammatory responses in a cholesterol-independent manner by interfering with endothelial adhesion and leukocyte migration to sites of inflammation (16). In rats with normal blood cholesterol levels, simvastatin was found to ameliorate immunopathology in an acute TNBS colitis model by blocking neutrophil accumulation in the small intestine and lowering serum TNF- $\alpha$ level (17). Lee et al show Simvastatin blocked TNF-alphainduced NF-kappaB transcriptional activity, IkappaB phosphorylation/degradation and DNA binding activity of NF-kappaB. Administration of simvastatin significantly reduced the severity of dextran sulfate sodium (DSS)-induced murine colitis as assessed by body weight, colon length and histology in a dosedependent manner (18). Bereswill et al show that after peroral administration of Simvastatin, mice were protected from acute ileitis development. Simvastatin treated animals displayed significantly increased numbers of regulatory T cells and augmented intestinal epithelial cell proliferation/regeneration in the ileum mucosa compared to placebo control animals. In contrast, mucosal $\mathrm{T}$ lymphocyte and neutrophil granulocyte numbers in treated mice were reduced. In addition, levels of the anti-inflammatory cytokine IL-10 in ileum, mesenteric lymph nodes and spleen were increased whereas pro-inflammatory cytokine expression (IL-23p19, IFN- $\gamma$, TNF- $\alpha$, IL-6, MCP-1) was found to be significantly lower in the ileum of treated animals as compared to Placebo controls (19). One of the factors participating in the initiation and perpetuation of inflammation in IBD may be an inappropriate production of antiinflammatory cytokines, resulting in a disturbed balance of proinflammatory versus anti-inflammatory cytokines. Although increased levels of IL-1 and an imbalance between IL-1 and IL-1Ra have been documented, the role of other IL-1 modulators in IBD has not yet been elucidated. An imbalance between the production of IL-1 and IL-1Ra has been described in freshly isolated intestinal mucosal cells and in colonic mucosal biopsies obtained from inflamed intestinal tissue of IBD patients (20). Administration of recombinant IL-1Ra prevents mucosal inflammation and necrosis in a rabbit model of dextran-induced colitis (21). Conversely, neutralization of endogenous IL-1Ra increases the severity of intestinal inflammation, indicating that endogenous IL-1Ra plays an anti-inflammatory role. The importance of IL-1 and IL-1Ra in the pathogenesis of IBD has been corroborated by the association between carriage of IL-1RN allele 2, low production of IL-1Ra and severity of disease in UC patients (22). Maeda et al show mucosal imbalance of interleukin-1 $\beta$ and interleukin-1 receptor antagonist in canine inflammatory bowel disease. A significant decrease in the intestinal IL-1Ra: IL-1 $\beta$ ratio of mRNA and protein was observed in IBD cases when compared with healthy control dogs (23). Our data demonstrate ability of ARIL-1 to influence the level of expression of pattern recognition receptors and show therefore potential in the correction of immune disorders in IBD. Characteristically, ARIL-1 operates as pure antagonist by blocking communication between the molecules of IL-1 (IL-1-alpha, IL-1-beta) and IL-1 receptor that allows providing effective control for the whole IL-1 system in the body.

\section{Acknowledgements}

The authors thank Inna Topol and Anna Degen for excellent technical assistance.

\section{References}

1. Kaser A, Zeissig S, Blumberg RS. Inflammatory bowel disease. Annu Rev Immunol. 2010; 28:573-621. PMID: 20192811

2. Song DH, Lee JO. Sensing of microbial molecular patterns by Toll-like receptors. Immunol Rev. 2012; 250(1):216-29. PMID: 23046132

3. Greenwood J, Steinman L, Zamvil SS. Statin therapy and autoimmune disease: from protein prenylation to immunomodulation. Nat Rev Immunol. 2006; 6(5):358-70. PMID: 16639429

4. Ludwiczek O, Vannier E, Borggraefe I, Kaser A, Siegmund B, Dinarello CA, et al. Imbalance between interleukin-1 agonists and antagonists: relationship to severity of inflammatory bowel disease. Clin Exp Immunol. 2004; 138(2):323-9. PMID: 15498044 
5. Yamada T, Deitch E, Specian RD, et al. Mechanisms of acute and chronic intestinal inflammation induced by indomethacin. Inflammation. 1993; 17:641-62. PMID: 7906675

6. Hausmann M, Kiessling S, Mestermann S, Webb G, Spottl T, Andus T, et al. Toll-like receptors 2 and 4 are up-regulated during intestinal inflammation. Gastroenterology. 2002; 122(7):19872000. PMID: 12055604

7. Lee JY, Kim JS, Kim JM, Kim N, Jung HC, Song IS, Simvastatin inhibits NF-kappaB signaling in intestinal epithelial cells and ameliorates acute murine colitis. Int Immunopharmacol.. 2007; 7(2):241-8. PMID: 17178392

8. Medzhitov R, Preston-Hurlburt P, Janeway CA. A human homologue of the Drosophila Toll protein signals activation of adaptive immunity. Nature. 1997; 388(6640):394-7. PMID: 9237759

9. Matsuguchi T, Takagi K, Musikacharoen T, Yoshikai Y. Gene expressions of lipopolysaccharide receptors, toll-like receptors 2 and 4 , are differently regulated in mouse $\mathrm{T}$ lymphocytes. Blood. 2000; 95(4):1378-85. PMID: 10666214

10. Mansson A, Adner M, Cardell LO. Toll-like receptors in cellular subsets of human tonsil T cells: altered expression during recurrent tonsillitis. Respir Res. 2006; 7:36. PMID: 16504163

11. Kabelitz D. Expression and function of Toll-like receptors in T lymphocytes. Curr Opin Immunol. 2007; 19(1):39-45. PMID: 17129718

12. Fukata M, Breglio K, Chen A, Vamadevan AS, Goo T, Hsu D, et al. The myeloid differentiation factor 88 (MyD88) is required for $\mathrm{CD} 4+\mathrm{T}$ cell effector function in a murine model of inflammatory bowel disease. J Immunol. 2008; 180(3):1886-94. PMID: 18209086

13. Tomita T, Kanai T, Fujii T, Nemoto Y, Okamoto R, Tsuchiya $\mathrm{K}$, et al. MyD88-dependent pathway in $\mathrm{T}$ cells directly modulates the expansion of colitogenic CD4+ T cells in chronic colitis. J Immunol. 2008; 180(8):5291-9. PMID: 18390710

14. Gonzalez-Navajas JM, Fine S, Law J, Datta SK, Nguyen KP, $\mathrm{Yu} \mathrm{M}$, et al. TLR4 signaling in effector CD4+ T cells regulates TCR activation and experimental colitis in mice. J Clin Invest. 2010; 120(2):570-81. PMID: 20051628
15. Harrington LE, Hatton RD, Mangan PR, Turner H, Murphy TL, Murphy KM, et al. Interleukin 17-producing CD4+ effector T cells develop via a lineage distinct from the Thelper type 1 and 2 lineages. Nat Immunol. 2005; 6(11):1123-32. PMID: 18023589

16. Maher BM, Dhonnchu TN, Burke JP, Soo A, Wood AE, Watson RW. Statins alter neutrophil migration by modulating cellular Rho activity a potential mechanism for statins-mediated pleotropic effects? J Leukoc Biol. 2009; 85(1):186-93. PMID: 18840670

17. Jahovic N, Gedik N, Ercan F, Sirvanci S, Yüksel M, Sener G, et al. Effects of statins on experimental colitis in normocholesterolemic rats. Scand. J Gastroenterol. 2006; 41(8):954-62. PMID: 16803694

18. Lee JY, Kim JS, Kim JM, Kim N, Jung HC, Song IS. Simvastatin inhibits NF-kappaB signaling in intestinal epithelial cells and ameliorates acute murine colitis. Int Immunopharmacol 2007; 7(2):241-8. PMID: 17178392

19. Bereswill S, Munoz M, Fischer A, Plickert R, Haag LM, Otto $\mathrm{B}$, et al. Anti-inflammatory effects of resveratrol, curcumin and simvastatin in acute small intestinal inflammation. PLoS One. 2010; 5(12). PMID: 21151942

20. Ishizuka K, Sugimura K, Homma T, Matsuzawa J, Mochizuki $\mathrm{T}$, Kobayashi $\mathrm{M}$, et al. Influence of interleukin-10 on the interleukin-1 receptor antagonist/interleukin-1 beta ratio in the colonic mucosa of ulcerative colitis. Digestion. 2001; 63 Suppl 1:22-7. PMID: 11173905

21. Youngman KR, Simon PL, West GA, Cominelli F, Rachmilewitz D, Klein JS, et al. Localization of intestinal interleukin 1 activity and protein and gene expression to lamina propria cells. Gastroenterology. 1993; 104(3):749-58. PMID: 8440434

22. Tountas NA, Casini-Raggi V, Yang H, Di Giovine FS, Vecchi M, Kam L, et al. Functional and ethnic association of allele 2 of the interleukin-1 receptor antagonist gene in ulcerative colitis. Gastroenterology. 1999; 117(4):806-13. PMID: 10500062

23. Maeda S, Ohno K, Nakamura K, Uchida K, Nakashima K, Fukushima $\mathrm{K}$, et al. Mucosal imbalance of interleukin-1 $\beta$ and interleukin-1 receptor antagonist in canine inflammatory bowel disease. Vet J. 2012; 194(1):66-70. PMID: 22483380 